\title{
Arctic Sea Ice: Decadal Simulations and Future Scenarios Using BESM-OA
}

\author{
Fernanda Casagrande 1 , Paulo Nobre², Ronald Buss de Souza 3 , Andre Lanfer Marquez², \\ Etienne Tourigny', Vinicius Capistrano², Raquel Leite Mello \\ ${ }^{1}$ National Institute for Space Research, Earth System Science Centre, São José dos Campos, Brazil \\ ${ }^{2}$ National Institute for Space Research, Centre for Weather Forecasting and Climate Research, Cachoeira \\ Paulista, Brazil \\ ${ }^{3}$ National Institute for Space Research, Southern Center for Space Research, Santa Maria, Brazil \\ Email: fernanda.casagrande@inpe.br
}

Received 26 February 2016; accepted 26 April 2016; published 29 April 2016

Copyright (C) 2016 by authors and Scientific Research Publishing Inc.

This work is licensed under the Creative Commons Attribution International License (CC BY).

http://creativecommons.org/licenses/by/4.0/

(c) (i) Open Access

\begin{abstract}
Important international reports and a significant number of scientific publications have reported on the abrupt decline of Arctic sea ice and its impact on the Global Climate System. In this paper, we evaluated the ability of the newly implemented Brazilian Earth System Model (BESM-OA) to represent Arctic sea ice and sensitivity to $\mathrm{CO}_{2}$ forcing, using decadal simulations (1980-2012) and future scenarios (2006-2100). We validated our results with satellite observations and compared them to Coupled Model Intercomparison Project, Phase 5 (CMIP5) for the same numerical experiment. BESM results for the seasonal cycle are consistent with CMIP5 models and observations. However, almost all models tend to overestimate sea ice extent in March compared to observations. The correct evaluation of minimum record of sea ice, in terms of time, spatial and area remains a limitation in Coupled Global Climate Models. Looking to spatial patterns, we found a systematic model error in September sea ice cover between the Beaufort Sea and East Siberia for most models. Future scenarios show a decrease in sea ice extent in response to an increase in radiative forcing for all models. From the year 2045 onwards, all models show a dramatic shrinking in sea ice and ice free conditions at the end of the melting season. The projected future sea ice loss is explained by the combined effects of the amplified warming in northern hemisphere high latitudes and feedbacks processes.
\end{abstract}

\section{Keywords}

Arctic Sea Ice, Climate Models, Brazilian Earth System Model 


\section{Introduction}

Sea ice is an important and complex component of the global climate system acting both as an indicator as well as an amplifier of climate change [1]-[3]. Notz and Marotzke [4] and Doescher et al. [5], indicate that sea ice cover is a more robust indicator of climate change than temperature trends alone, because sea ice changes depend on integrated changes in atmospheric and ocean variables with non linear impacts, on various temporal and spatial scales under global climate forcing.

Over the last 30 years, abrupt changes in sea ice have become evident in the Arctic, especially in the summer months of 2007 and 2012 when Sea Ice Extent (SIE) reached a minimum record extent of $4.2 \times 10^{6} \mathrm{~km}^{2}$ and $3.4 \times$ $10^{6} \mathrm{~km}^{2}$, respectively. Satellite data have shown that the sea-ice loss has happened faster than forecasted and is unprecedented in the past 1.5 millennia [1] [6]-[8].

Sea ice age and sea ice thickness also have decreased rapidly resulting in a sea ice more sensitive to dynamic and thermodynamic forcing [1] [7]. There is an agreement among scientists about the direct relationship between the shrinking of the Arctic sea ice and global warming. According to Holland and Bitz [3] and Curry et al. [9], the range of simulated polar warming is from 1.5 to 4.5 times the global mean warming and is widely related to the sea ice-albedo feedback mechanism. Most of the climate models agree that the global air temperature will continue to rise, particularly in northern high latitudes and the Arctic will become ice free in the summer in approximately 30 years, as a response to an increase in atmospheric greenhouse gas concentrations [1] [5]. The impacts of melting sea ice in recent and future decades have not yet been fully understood and accurately quantified. Nonetheless, recent studies suggest that sea ice loss is linked to cold winter extremes in the northern continents, hot summer extremes over mid-latitudes continents, as well as wet summers and flooding in Eurasia [10]-[13].

Besides the important role of sea ice in the climate system, knowing the dynamics and geographical sea ice cover is also essential for human activities such as navigation, oil exploration and fishery [14] [15]. According to Cochran et al. [16] and Meier et al. [15], changes in Arctic threaten the infrastructure, health and safety of the Arctic indigenous people as well as present a significant risk to local marine biodiversity

According to Whiteman et al. [17], sea ice changes will affect all nations, not just those in the world's far north, and all should be concerned about changes that are happening in the Arctic region. In that sense, Global Climate Models, even with inherent uncertainties and limitations are powerful tools for better understanding the changes in sea ice as well as providing future scenarios to guide decision markers, governments and local communities among others.

The recent development of the Brazilian Earth System Model (BESM) is an effort of several institutions and researchers lead by the Brazilian National Institute for Space Research (INPE) to build a multidisciplinary research framework with the intent to understand the causes of global climate change, its effects and its impacts on society. The BESM model, also aims to contribute to Program for Climate Model Diagnostics and Intercomparison (PCMDI) with short-term and long-term simulations, as well as to provide futures scenarios of climate change [18]. Based on several studies and reports [5] [14] [17] [19] and understanding the importance of sea ice in the global climate system and the global economy, BESM simulations are expected to contribute with, among other variables, sea ice short and long-term simulations. BESM simulations can also be useful for future studies on ocean-atmosphere-sea ice coupling processes and impacts of sea ice loss around the world.

In this paper, we evaluated decadal simulations (1980-2012) and future scenarios (2006-2100) of SIE as simulated by two versions of the BESM and by other Coupled General Circulation Models participating in the Coupled Model Intercomparison Project, Phase 5 (CMIP5). Our goal is to evaluate the first results on the ability of BESM to represent past and future sea ice changes and sensitivity of the sea ice to the radiative forcing, using the Taylor protocol [20] [21]. The paper is structured as follows: first, we present the data sources in Section 2. Then, in Section 3, we examine the seasonal cycle, the spatial pattern and the minimum records of the Arctic sea ice, comparing the BESM decadal simulations to satellite observations and other CMIP5 models. In Section 4, we investigate the future scenarios for two different versions of BESM and the CMIP5 models, using two different scenarios, the Representative Concentration Pathway RCP4.5 and RCP8.5. We discuss the results and also indicate possible causes to explain the differences between the sea ice variation using BESM versions 2.3 and 2.5. Finally, in Section 5 we present our conclusions and lay out our recommendations for future work.

\section{Data Sources}

This study uses short-term simulations (decadal hindcasts) and long-term simulations (future scenarios) of 11 
state-of-the-art General Circulation Models (GCMs) and Earth System Models (ESMs), seen in Table 1. The numerical experiment design follows the CMIP5 protocol, for decadal data and future projections based on the Taylor protocol [20] [21]. CMIP is an international effort of the scientific community to provide simulations of many different climate models in order to better understand past and future climate changes as well to provide a scientific data set for the Intergovernmental Panel on Climate Change (IPCC).

The BESM ensemble members of the decadal simulations were integrated for 10 years, each with initial conditions (IC) on 1 - 10 December of the years 1960, 1965, 1970, 1975, 1980, 1985, 1990, 1995, 2000 and 2005. Three of these ensembles (1960, 1990 and 2005) were extended for an extra 20 years for each of the 10 members, completing 30 years long integrations each. These simulations used atmospheric CO2 concentrations derived from in situ air samples collected at Mauna Loa Observatory, Hawaii [18]. The Atmospheric model initial conditions for each ensemble member used the National Centers for Environmental Prediction (NCEP-NCAR) reanalysis fields for the 0000 UTC of each day from 1 to 10 December of the chosen years. The ocean initial states were chosen from the same dates from a spinup run of MOM4p1 that used prescribed atmospheric fields of momentum, solar radiation, air temperature, and freshwater described in Nobre et al. [18].

The future scenarios are defined by the Representative Concentration Pathways (RCPs) and each RCP defines a specific emissions trajectory and subsequent radiative forcing. The radiative forcing values in the year 2100 relative to pre-industrial values are $4.5 \mathrm{~W} \cdot \mathrm{m}^{-2}$ and $8.5 \mathrm{~W} \cdot \mathrm{m}^{-2}$ for RCP4.5 and RCP8.5 respectively, which include the period from 2006 to 2100 . The $\mathrm{CO}_{2}$ concentration in the year 2100 for each RCP is approximately 600 ppm and $1300 \mathrm{ppm}$ for RCP4.5 and RCP8.5, respectively.

We compared BESM results with CMIP5 models simulations using the same numerical experiment setup. Still, the models differ in spatial resolution, physical component and parameterizations. For decadal simulations we chose to work with time series from 1980 to 2012 due to the availability of satellite observations for comparison. The SSM/I (Special Sensor Microwave Imager) satellite observations obtained from the National Snow and Ice Data Center (NSIDC) were used to validate the numerical simulations. For all simulations we calculated the SIE, defined as the area where the sea ice concentration is greater than $15 \%$ in a grid.

\section{Table 1. CMIP5 main characteristics.}

\begin{tabular}{|c|c|c|c|}
\hline Institute/Country & Model & Experiment Design & Reference \\
\hline $\begin{array}{l}\text { National Institute for Space Research } \\
\text { (INPE)-Brazil }\end{array}$ & $\begin{array}{c}\text { Brazilian Earth System Model } \\
\text { BESM-OAV2.3 } \\
\text { BESM-OA-V2.5 }\end{array}$ & $\begin{array}{c}\text { Decadal } \\
\text { RCP45/RCP85 }\end{array}$ & [18] \\
\hline $\begin{array}{l}\text { Canadian Centre for Climate Modelling } \\
\text { and Analysis (CCCma)-Canada }\end{array}$ & $\begin{array}{c}\text { Canadian Coupled Climate Model, } \\
\text { versions } 4 \text { and ESM2 } \\
\text { CanCM4 } \\
\text { CanESM2 }\end{array}$ & $\begin{array}{c}\text { Decadal } \\
\text { RCP45/RCP85 }\end{array}$ & [22] [23] \\
\hline $\begin{array}{l}\text { National Oceanic and Atmospheric } \\
\text { Administration-Geophysical Fluid Dyanmics } \\
\text { Laboratory (GFDL-NOAA)-USA }\end{array}$ & $\begin{array}{l}\text { Geophysical Fluid Dyanmics } \\
\text { Laboratory-Climate Models } \\
\text { GFDL-CM2.1 } \\
\text { GFDL-CM3 }\end{array}$ & $\begin{array}{c}\text { Decadal } \\
\text { RCP45/RCP85 }\end{array}$ & [24] [25] \\
\hline $\begin{array}{c}\text { Met office Hadley Centre (Met Office) } \\
\text { United Kingdom }\end{array}$ & $\begin{array}{c}\text { Hadley Centre Coupled Model } \\
\text { HadCM3 } \\
\text { HadGEM2-ES }\end{array}$ & $\begin{array}{c}\text { Decadal } \\
\text { RCP45/RCP85 }\end{array}$ & [26] [27] \\
\hline $\begin{array}{l}\text { Atmospheric and Ocean Research } \\
\text { Institute-University of Tokyo (AORI)-Japan }\end{array}$ & $\begin{array}{l}\text { Model for Interdisciplinary } \\
\text { Research on Climate } \\
\text { MIROC } 5\end{array}$ & RCP45/RCP85 & [28] \\
\hline $\begin{array}{l}\text { Max Planck Institute for Meteorology } \\
\text { (MPI)-German }\end{array}$ & $\begin{array}{l}\text { Max Planck Institute-Earth } \\
\text { System Model } \\
\text { MPI-ESM-LR }\end{array}$ & $\begin{array}{c}\text { Decadal } \\
\text { RCP45/RCP85 }\end{array}$ & [29] \\
\hline $\begin{array}{l}\text { National Centre for Atmospheric } \\
\text { Research (NCAR)-USA }\end{array}$ & $\begin{array}{l}\text { Community Climate System } \\
\text { Model Version } 4 \\
\text { CCSM4 }\end{array}$ & $\begin{array}{c}\text { Decadal } \\
\text { RCP45/RCP85 }\end{array}$ & [30] \\
\hline
\end{tabular}




\section{BESM-OA Model}

In this work, we used two versions of the BESM Coupled Ocean Atmosphere (BESM-OA) model: BESM-OA V2.3 for decadal and RCP simulations and BESM-OA V2.5 for RCP simulations only. The main differences between these two versions are the microphysics scheme proposed by Ferrier et al. [31] and a new surface layer scheme based on Jimenez and Dudhia [32] described by Capistrano et al. [33] [34].

Both BESM versions used in this research are composed of the INPE/CPTEC atmospheric general circulation model (AGCM) coupled to NOAA/GFDL's Modular Ocean Model version 4p1 (MOM4p1) oceanic general circulation model (OGCM) via GFDL's Flexible Modular System [18] [35] [36]. The INPE/CPTEC AGCM has a spectral horizontal resolution truncated at triangular wave number 62, giving an equivalent grid size of 1.8758 degrees of latitude and longitude and 28 sigma levels unevenly spaced in the vertical (i.e., T062L28). The exchanges of heat, moisture and momentum between the surface and atmosphere in INPE/CPTEC AGCM over the ocean and continents are computed differently by various physical processes that define the surface fluxes.

The ocean model MOM4p1 [35] from GFDL, includes the Sea Ice Simulator (SIS), described in Winton [37]. The SIS is a dynamical model with three vertical layers (two ice and one snow), and five ice thickness categories. The elastic-viscous-plastic technique of Hunke and Dukowicz [38] is used to calculate ice internal stresses, and the thermodynamics is a modified Semtner's three-layer scheme [39]. SIS calculates the concentration, thickness, temperature, brine content, and snow cover of an arbitrary number of sea ice thickness categories (including open water) as well the motion of the complete pack. Additionally, the model is responsible for calculating ice/ocean fluxes and communicating fluxes between the ocean and atmosphere models globally.

The MOM4p1 horizontal grid resolution is set to $1^{\circ}$ in the longitudinal direction, and in the latitudinal direction the grid spacing is $1 / 4^{\circ}$ in the tropical region $\left(10^{\circ} \mathrm{S}-10^{\circ} \mathrm{N}\right)$, decreasing uniformly to $1^{\circ}$ at $45^{\circ}$ and to $2^{\circ}$ at $90^{\circ}$ in both hemispheres. For the vertical axis, 50 levels are adopted with a $10 \mathrm{~m}$ resolution in the upper $220 \mathrm{~m}$, increasing gradually to about $370 \mathrm{~m}$ of grid spacing in deeper layers. We used FMS to coupling MOM4p1 and CPTEC/AGCM. Thus, wind stress fields are computed, using Monin-Obukhov scheme within MOM4p1, from the field 10 meters above the above the ocean surface. Adjustments were done to the Monin-Obukhov boundary layer scheme, whose parameters were tuned according to the wind fields output by the CPTEC AGCM. The AGCM receives the following two fields from the coupler: sea surface temperature (SST) and ocean albedo from ocean and sea ice models at an hourly rate (coupling time step). Adjustments were also made to ocean shortwave penetration parameters due to the CTPEC AGCM supply of visible and infrared short wave radiation. The coupling variables supplied by the AGCM are as follows: freshwater (liquid and solid precipitation), specific humidity, heat, vertical diffusion of velocity components, momentum fluxes, and surface pressure.

The microphysics of Ferrier et al. [31] used in BESM-OA V2.5, replaced the Large Scale Precipitation scheme used in BESM-OA V2.3. This new microphysics scheme computes changes in water vapor, cloud water, rain, cloud ice and precipitation ice. Also, BESM-OA V2.5 uses a new surface layer scheme based on Jimenez and Dudhia [32] and described by Capistrano et al. [33] [34]. In this scheme, the surface and the first AGCM level values are used to assess wind, air temperature and humidity at $10 \mathrm{~m}$. The changes introduced lead to a more consistent surface layer formulation that resulted in a near-surface wind, air temperature and humidity more consistent with observations than previous BESM version. This occurs mainly over the ocean, where those variables are important to compute the heat fluxes at ocean-atmosphere interface.

\section{Results and Discussion}

\subsection{Seasonal Cycle}

Seasonal melt-freeze transitions are important to continuously monitor sea ice over the Arctic. Sea ice formation, growth and decay are closely related to air temperature, ocean heat content, albedo and heat fluxes and hence can vary strongly from month to month [5] [40].

Thus, we present in this section the Arctic seasonal cycle of sea ice, in order to better understand the differences between the models studied, with a focus on the performance of the BESM-OA V2.3 model.

First, to understand the ability of BESM-OA V2.3 to simulate the seasonal cycle in relation to observation and other CMIP5 models, we present in Figure 1 the seasonal cycle of climatological average of SIE from CMIP5 model and observed values for the period from 1980 to 2010.

All of the models were able to represent the seasonal cycle of the Arctic sea ice. Large oscillations between 


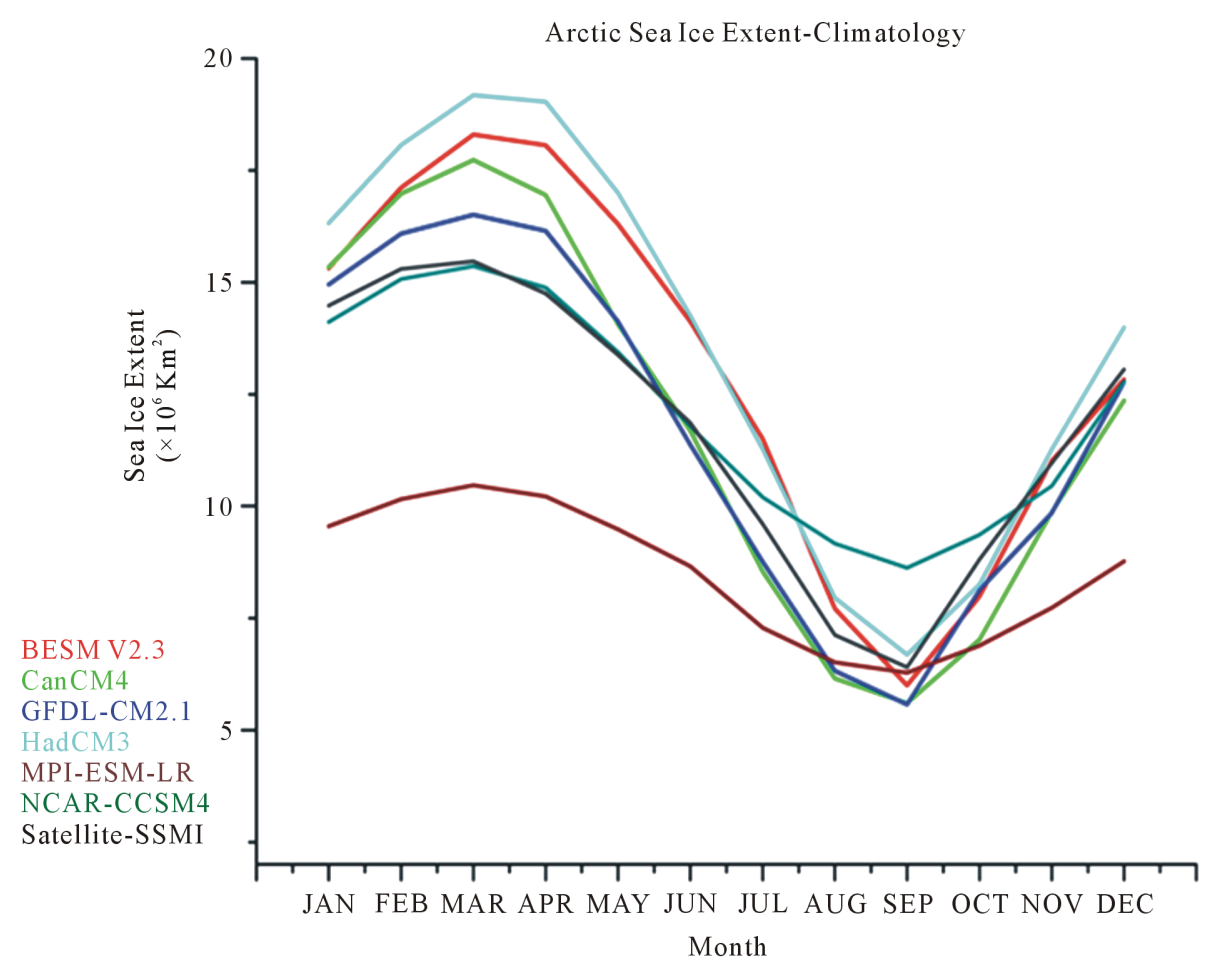

Figure 1. Climatology of SIE (1980 to 2010) in the northern hemisphere simulated by BESMOA V2.3, CMIP5 models and observations.

summer and winter are evident, with sea ice growing from autumn and winter reaching a peak in March, and then declining throughout spring and summer as the melting season progresses.

However, most models overestimate SIE values in winter (except the MPI-ESM-LR model), and underestimate in summer (except HadCM3 and NCAR-CCSM4). BESM-OA V2.3 ensemble agrees quite well with observations and satisfactorily represents the seasonality of sea ice, although the model's sea ice decays more rapidly than observed in summer and autumn. The observational data (BESM-OA V2.3) shows that Arctic SIE varies between approximately $15 \times 10^{6} \mathrm{~km}^{2}\left(18 \times 10^{6} \mathrm{~km}^{2}\right)$ at winter maximum and $6 \times 10^{6} \mathrm{~km}^{2}\left(6 \times 10^{6} \mathrm{~km}^{2}\right)$ at summer minimum.

The difference between the model's performance for winter and summer are in agreement with [1] [26] [41] [42]. It is clear that the BESM-OA V2.3 model, even with an overestimation during winter presents a very good agreement in summer when SIE reaches critical values.

Based on our results, Sortberg et al. [42] and Karlsson and Svensson [43], we suggest the following scheme to explain the differences between winter and summer model's performance in representing SIE. First, the presence of sea ice affects strongly the sea ice albedo, which has a key influence on the energy budget and is directly linked to the cloud-albedo effect and cloud-radiation effect. Clouds are linked with the energy budget by reflecting shortwave radiation back to space, trapping Longwave (LW) radiation and radiating it back to the surface, providing one of more the strongest feedbacks in the climate system [44]. Second, in wintertime, the amount of solar radiation is low or non-existent and the ability of the clouds to reemitted LW to the surface presents a positive cloud radiative effect on the surface energy budget. On the other hand, during the seasons with solar radiation, the positive greenhouse effect is competing with a negative cloud albedo effect, because the clouds decrease the amount of incident solar radiation at the surface. Finally, recent publications using CMIP3 and CMIP5 models [42] [43] suggest that models generally have the tendency to underestimate the amount of LW radiation reemitted back to the surface in winter. As a consequence of these processes, the models tend to overestimate SIE in wintertime. Additionally, the annual amplitude of sea ice cover depends inversely on the model's sea ice albedo [42] [43]. BESM-OA V2.3 results agree with this scheme, as both downward and upward LW radiation at the surface are underestimated in winter. The ensemble mean is lower than the mean of the observations by approximately $30 \mathrm{~W} \cdot \mathrm{m}^{-2}$ (not shown). Another notable example is related to the MPI-ESM-LR 
model's performance, which presents a high sea ice albedo and low annual amplitude of sea ice. According to Wild et al. [45], the bias in LW radiation depends on the climate conditions and is not geographically uniform, with higher (smaller) bias in cold and dry climates (warm and humid climates) with low (high) downward LW radiation emission.

Stroeve et al. [1], Knutti and Sedlacek [46] and Li et al. [44], assessed the evolution between CMIP3 and CMIP5 and showed an improvement in the Arctic sea ice prediction and radiation in CMIP5. Nevertheless, a better representation of sea ice depends also on improvements in the representation of the Arctic sea-ice albedo, clouds, cloud-radiation effects and feedback processes.

Figure 2 shows a Taylor diagram for September, March and annual climatology of SIE. This diagram is a useful tool to compare observed and simulated data in terms of correlation coefficient, RMS and standard deviation. A shorter distance between model and REF (observed) in a Taylor Diagram indicates a better model's performance. For the annual values (black) all the six models have a correlation with the observations higher than 0.96, while for March and September the correlation coefficient presents low values, as expected. For all models (except MPI-ESM-LR) the correlation in March is smaller than 0.6. The annual cycle of SIE is quite well represented because the seasonal cycle of SIE was well represented by all the models as shown in Figure 1. However, when looking at separate months, the correlation drops, as consequence in the same month time series, only the interannual variability is being evaluated. For the month of March, we suggest the previously described scheme (radiation effect) to explain the low correlation between observation and models. To understand the low correlation in September, we suggest a relation with sea ice thickness. According to Shu et al. [47] and Stroeve [1], the sea ice thickness simulated in the CMIP5 models is too thin, resulting in enhanced sea ice melt and an

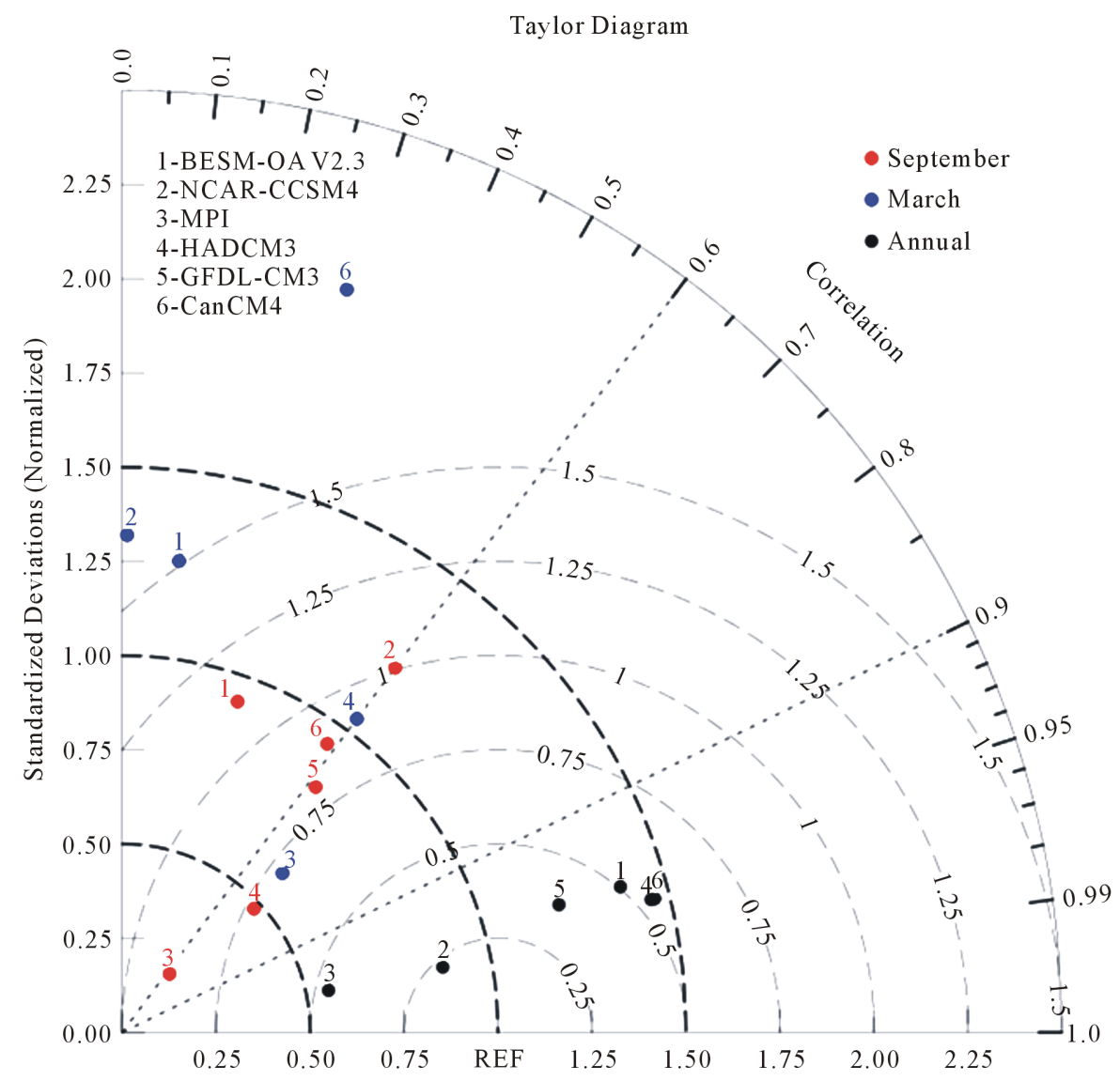

Figure 2. Taylor diagram of September, March and climatological annual cycle of SIE for the period 1980-2012. The x-axis and y-axis is the standard deviation normalized. The correlation coefficient between observations and each model is given by the azimuthal position. The centered RMS difference between simulated and observed is proportional to their distance one from another. 
underestimation fo SIE in summertime, as shown in Figure 1. BESM-OA V2.3 agrees with Shu et al. [47], showing an underestimate in sea ice thickness, notably greater in the marginal sea ice zones (not shown).

\subsection{Spatial Pattern}

Several studies have compared the observed SIE variation using climate models and CMIP data sets in a seasonal cycle or time series approach [1] [6] [41]. This type of analysis is important to know the model's ability to predict SIE. However, when considering only SIE, the information related to spatial pattern is lost. Analyzing spatial patterns avoids overconfidence in the predictions and excludes compensation of errors of opposite sign in different regions [48]. Cavalieri and Parkinson [49] also show the importance of evaluating the Arctic Ocean by regions. The authors, using satellite data set to analyze sea ice variability and trends from 1979 to 2010, found that trends for nine distinct regions in the Arctic are not homogeneous and indicated the complex nature of the Arctic climate system by regions.

Figure 3 shows September average Sea Ice Cover (SIC) observations over the study area. The spatial difference between modeled and observed SIC in September average is shown in Figure 4. September was chosen because commonly is when sea ice reaches its annual minimum over the Arctic.

Despite obvious inter-model differences depicted in Figure 4, there is a reasonable agreement between all the models. Most models tend to well represent SIC in the central Arctic, whereas the opposite occurs in marginal ice zones. There is a general tendency to underestimate SIC in areas such as the Beaufort Sea and the East Siberian Sea (except for MPI-ESM-LR and HadCM3) suggesting a systematic model error in this region. However, NCAR-CCSM4 overestimates SIC in both Laptev and Kara Sea (Figure 4). This may reflect the NCAR model's overestimation observed for September and shown in Figure 1.

The SIC in the region between Canada and Greenland is well represented by BESM-OA V2.3, GFDL-CM2.1 and MPI-ESM-LR models, while SIC between East Siberia and the Barents Seas is only well simulated by

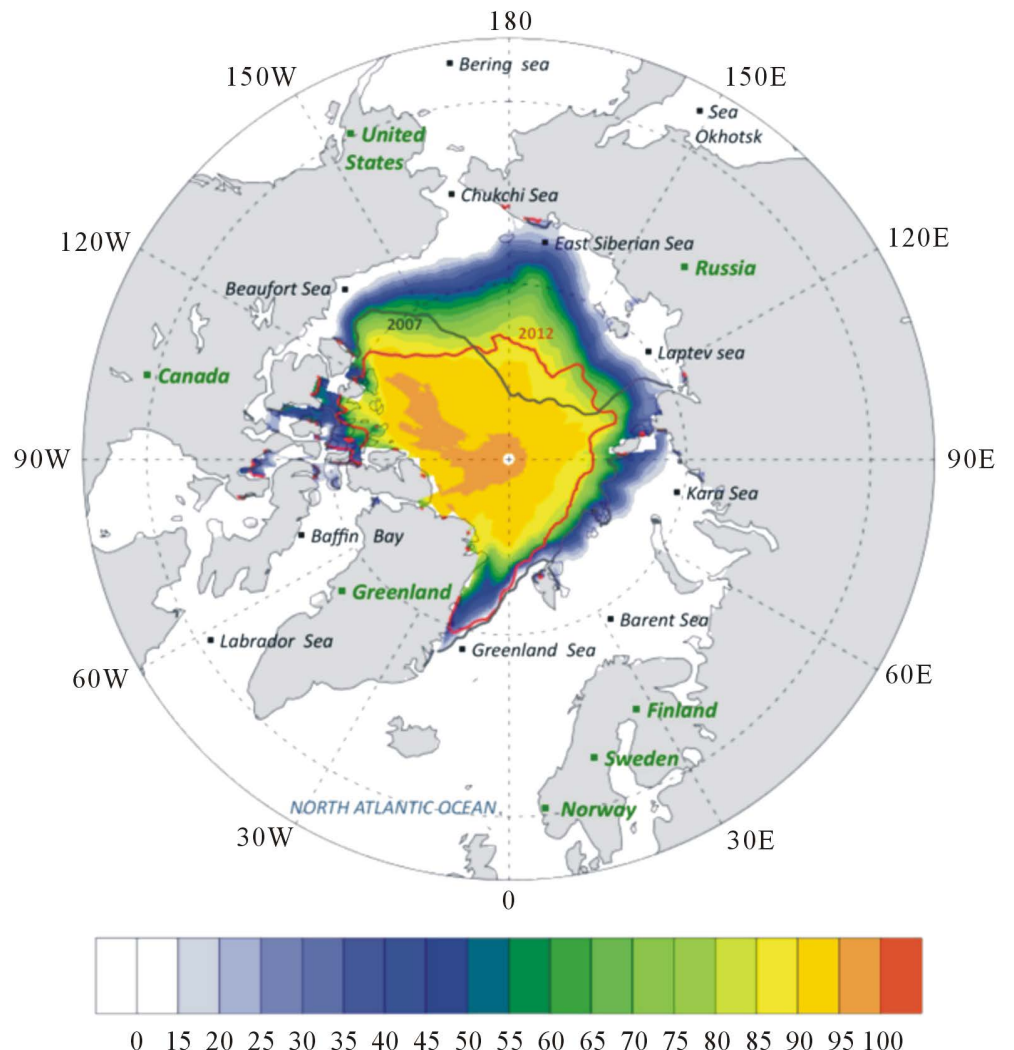

Figure 3. Arctic study area and September SIC Climatology (1980-2010) from satellite observations (shaded colors). Dark gray and orange lines refer to the 2007 and 2012 minimum events respectively. 

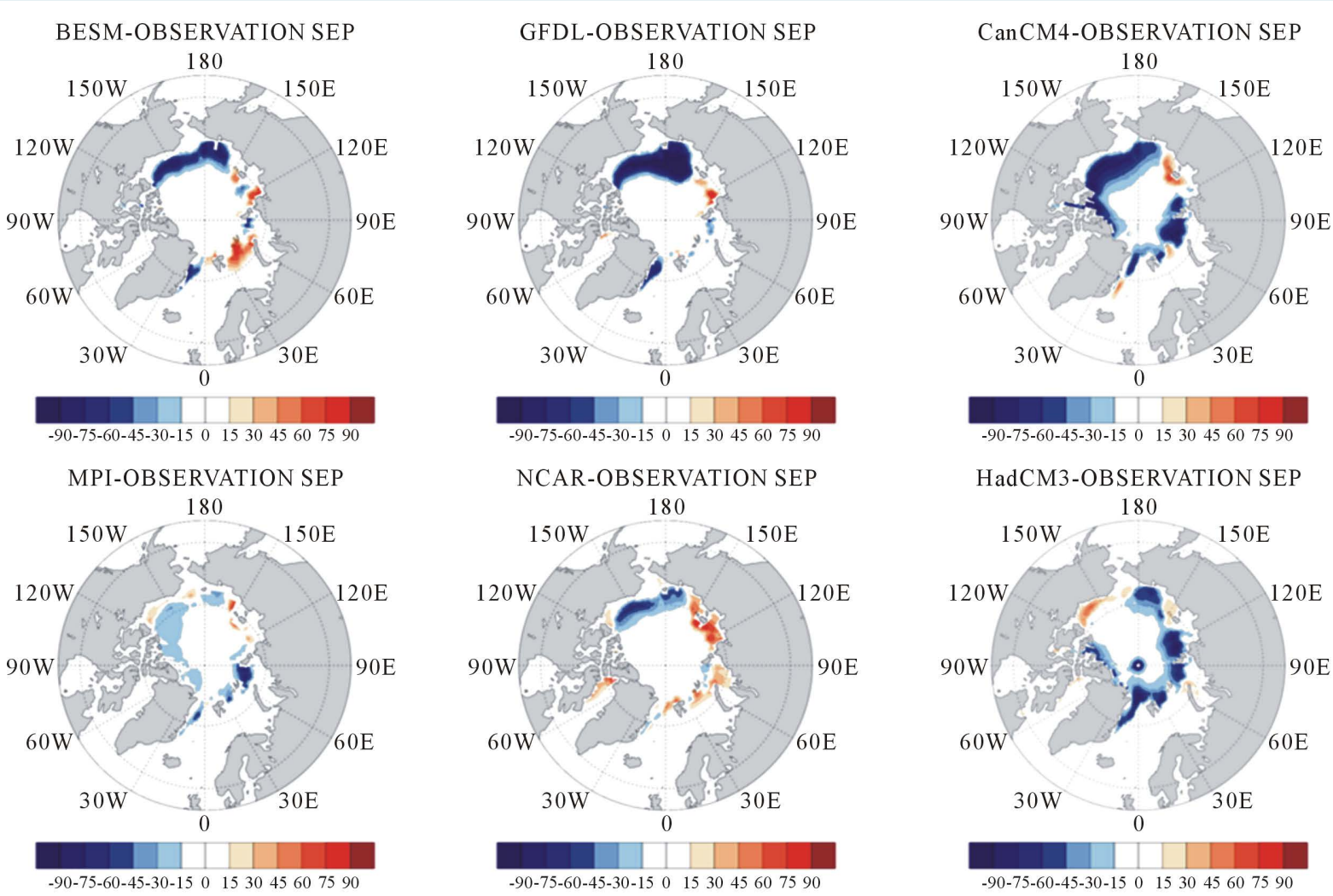

Figure 4. Difference between model simulations and observations for September SIC climatologic average from 1980 to 2010. BESM-OA V2.31, GFDL-CM2.1, CanCM4 (upper) MPI-ESM-LR, HadCM3, NCAR-CCSM4 (bottom). Positive (negative) value depicted in red (blue) represent areas where the model overestimates (underestimates) sea ice concentration values.

MPI-ESM-LR model. Despite a good representation of the spatial pattern of SIC in the MPI-ESM-LR model in September (Figure 4), it is clear that the amplitude of its annual cycle is smaller than both the others models and satellite observations (Figure 1). This reveals a certain deficiency in representing physical processes between ocean-atmosphere-sea ice, although the good representation during summer.

The detailed analysis of simulated SIC by regions using Climate Models is justifiable due to both economic and scientific reasons. Economically, as a result of sea ice loss maritime transports may gain two new routes with the opening of the "Northwest Passage" in Northern Canada and Greenland, and the "Northeast Passage" between Northern Russia and Norway [14]. This is considered a hot topic because these passages could lead to fast and cheaper ship transport between Europe and North America. Scientifically, this is relevant because the importance of properly account for the dynamical/thermodynamical processes taking place in shaping SIC over the Arctic region.

It is instructive to compare Figure 1 with Figure 4, analyzing only SIE in September for GFDL-CM2.1 and CanCM4 models (Figure 1). This can induce overconfidence in how well the models agree (SIE in both models are approximately $5.6 \times 10^{6} \mathrm{~km}^{2}$ ). However, when we look at the spatial patterns in Figure 4, we find quite different SIE distributions. CanCM4 model shows a large area of high negative values (especially between Greenland and Canada), whereas GFDL-CM2.1 shows a small area of high negative values only in parts of Beaufort Sea and East Siberian Sea. Thus, even some climate models showing a good performance in simulating SIE during summertime do not necessarily simulate a realistic spatial sea ice distribution.

\subsection{Minimum of Sea Ice Extent}

Changes in ice extent due to the seasonal cycle are so large that they tend to obscure any signal related to interanual variability. To remove the strong seasonal cycle, we again specifically focus on September since it shows the minimum annual of SIE. According to Doescher et al. [5], the ability to identify real changes in the Arctic 
Climate System increases when we focus on individual seasons. In this context, Figure 5 shows the SIE time series of September averages from 1982 to 2014.

Arctic sea ice has declined sharply during the last three decades, with record low summer ice cover in September 2007 and 2012 as illustrated in Figure 1. Here, we show the time series of SIE and analyze the ability of the models to represent recent changes.

Arctic SIE averages from 1980 to 2010 (Figure 5) show a noticeable decrease in Arctic SIE. September SIE simulated by BESM-OA V2.3 (satellite observations) between 2000 and 2010 was $4.2 \times 10^{6} \mathrm{~km}^{2}\left(5.7 \times 10^{6} \mathrm{~km}^{2}\right)$, while between 1980 and 1990 it was $6 \times 10^{6} \mathrm{~km}^{2}\left(7.1 \times 10^{6} \mathrm{~km}^{2}\right)$, showing a reduction of approximately $30 \%$ (19.8\%) in SIE. March SIE for example (not shown), although at a slower rate in comparison to September, also decreases with time.

The minimum satellite record of SIE occurred in September 2012, with $3.6 \times 10^{6} \mathrm{~km}^{2}$ against $4.5 \times 10^{6} \mathrm{~km}^{2}$ in BESM-OA V2.3. In 2012, satellite observations (GFDL-CM2.1) presented a decrease of 50.4\% (42.3\%) of SIE in relation to the 1980s decade. Except for the GFDL-CM2.1 model, no other model was able to well represent the observed 2012 minimum. However, BESM-OA V2.3 and CanCM4, generated episodes of low SIE in September with a magnitude and behavior comparable with the low observed in 2012. These episodes of minimum SIE occurred in 2006 and 2002 for the BESM-OA V2.3 and CanCM4 models, respectively. According to Doscher et al. [5] and Holland et al. [50], such abrupt sea ice loss resulted from a complex interplay between the thermodynamics and dynamics of sea ice, ocean and atmosphere and successful prediction requires careful initialization with ocean and sea ice conditions.

Figure 6 illustrates the spatial distribution of average September SIE (left) and minima of September SIE value found between 1980 and 2010 (right) for all the models evaluated in this work. This figure aimed to show the model's performance to represent the spatial pattern in episodes of low SIE, regardless of year.

Looking at the spatial patterns of the SIE climatological mean and minimum record, it is clear that the climate models are able to reproduce the seasonal cycle of the SIE (Figure 1 and Figure 2) better than they represent the minimum records. Only GFDL-CM2.1 model presents a good spatial agreement of minimum records with observation. This could be explained by two main reasons. First, it was the only one that matched the spatial pattern of the observed minimum, which may lead to a better agreement with observed meteo-oceanographic patterns (not studied here). Second, it may be related to a better representation of the sea ice and feedbacks processes in the parameterizations of the GFDL-CM2.1 model. Two other models (BESM-OA V2.3 and CanCM4) also show a reasonable spatial agreement with observations, although not as well as GFDL-CM2.1. These two models presented an underestimation of SIE, but presented a very good representation of the SIE in

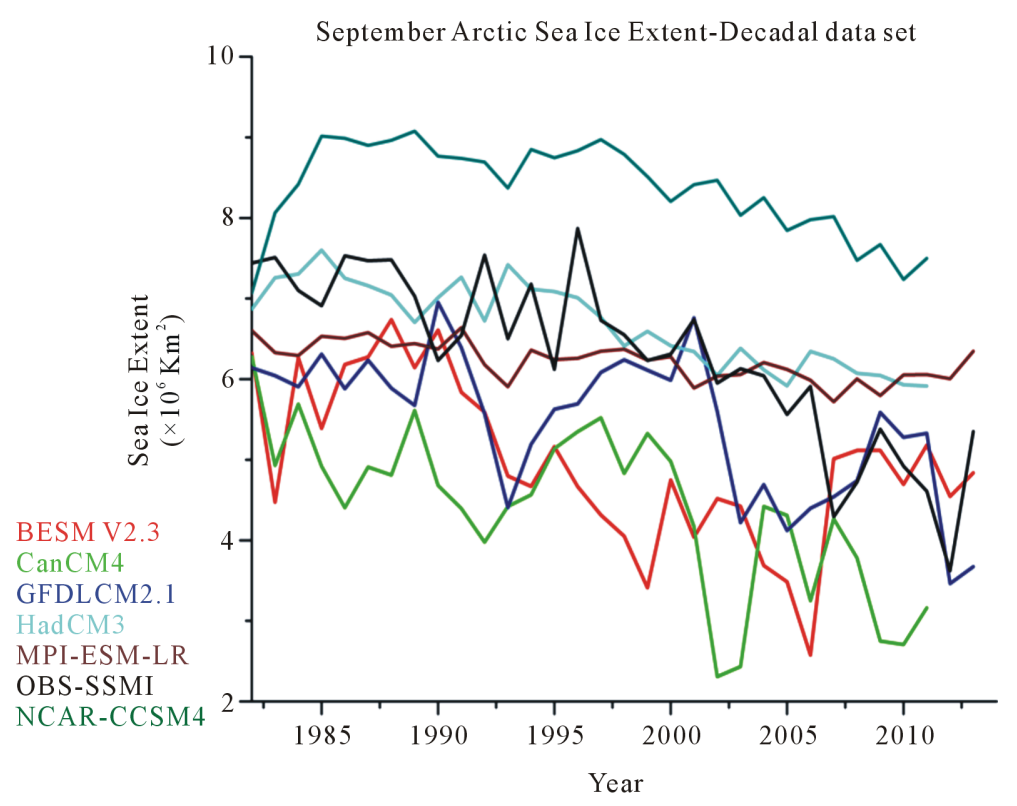

Figure 5. Arctic sea ice extent time series of September from 1980 to 2014 for CMIP5 models and observational data. 

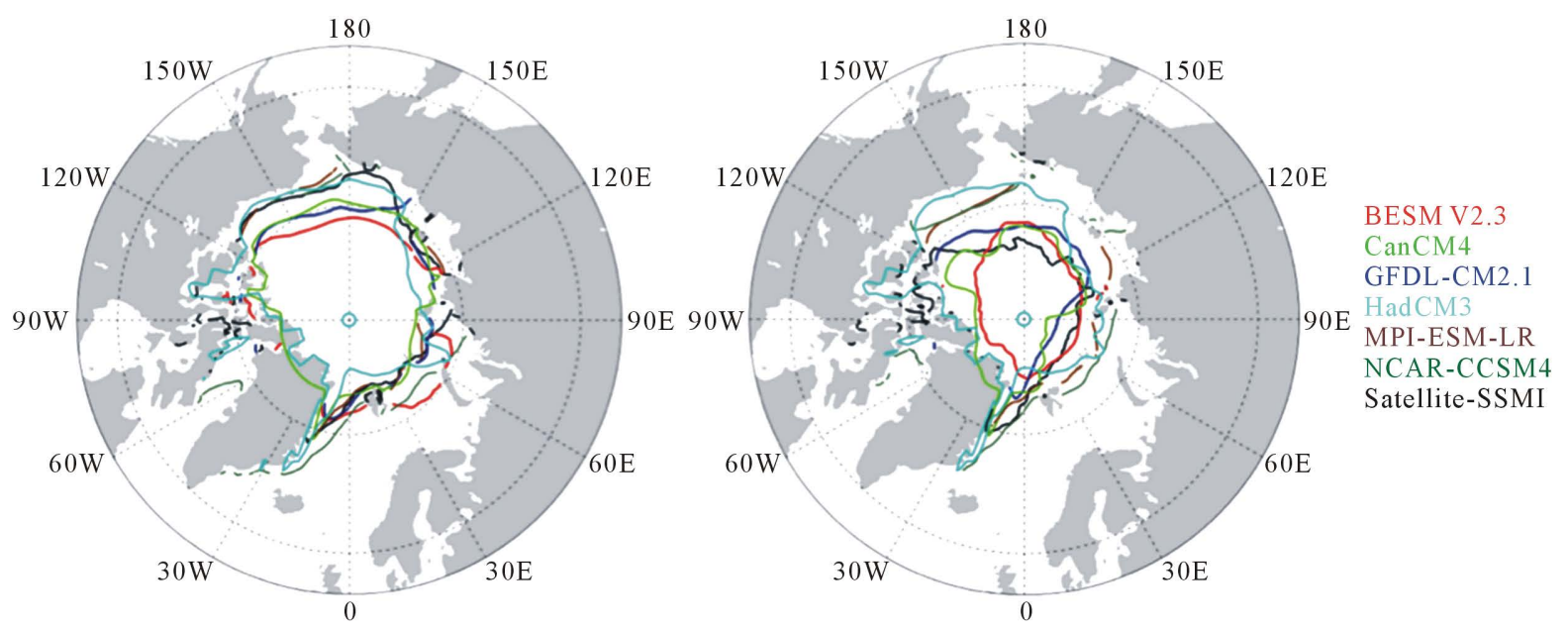

Figure 6. Spatial distribution of SIE average (left) and lowest values of September SIE found between 1980 to 2010, (right), for all CMIP5 models evaluated in this work.

the central Arctic region (Figure 6). The minimum record for the BESM-OA V2.3 shows a deficiency near Greenland and at the north of Canada. We understand that this happens because of the overestimation of Sea Surface Temperature (SST) in that region by the BESM-OA V2.3 model (not shown). Although BESM-OA V2.3 and CanCM4 were capable to capture the correct signature of the SIE minimum record with a decrease in SIE followed by an increase in the following year (Figure 5), the correct estimation of minimum SIE, in time, spatial, area and processes signatures remains a challenge for the modeling community.

Due to the sea ice retreat in recent Septembers months, ice cover in the following spring tends to be thinner, thus vulnerable to melting in summer. According to Doscher et al. [5], each record of low SIE is followed by a partial recovery. Additionally, Tietsche et al. [48] suggest that the minimum record of SIE during a single September is reversible, as the albedo sea ice mechanism is compensated by large scale recovery mechanisms. According to Vihma [51] the sea ice loss increases the heat flux from the ocean to the atmosphere in early winter and autumn. As result of this, a local increase of air temperature, humidity and cloud cover is expected thus reducing the stability of the atmospheric boundary layer.

Hunke et al. [52] evaluated the retrospective and new directions of sea ice models. The authors indicated some deficiencies in the dynamics (e.g. transport processes, dynamic coupling and mechanical redistribution) and thermodynamics (e.g. feedback processes and melt ponds) and suggested that improvements in the sea ice prediction dependent on improvements in the descriptions of the physical processes and characteristics, as well as, extending the models for Earth System Model simulations including biogeochemistry. According to Flocoo et al. [53] and Roeckner et al. [54], one of the processes, poorly represented in sea ice models, is the formation and evolution of melt ponds. Melt ponds affect the heat and mass balances of SIC, mainly by reducing albedo by up to $20 \%$. Consequentially, a reduction of the sea ice volume can reach $40 \%$, leading to further sea ice melt. At the end of the melting season, melt ponds cover up to $50 \%$ of the sea ice surface. A better representation of the melt pond scheme will improve the sea ice simulation and is essential for accurate future sea ice projections.

\subsection{Future Projection of Arctic Sea Ice}

The long-term evolution of SIE in the northern hemisphere as simulated by BESM and CMIP5 models, using RCP4.5 and RCP8.5 is shown in Figure 7. The simulations clearly show a decrease in SIE up to 2100, for all simulations and both RCPs. Arctic SIE decline with the increase of the radiative forcing in all models. The BESM-OA V2.3 control experiment (gray lines in Figure 7) reinforce that ice-free conditions only happen when external forcing from anthropogenic sources are include in climate model simulations. These results are in agreement with Stroeve et al. [1].

For September, at the beginning of the series (2006 to present-day), the HadGEM2 model SIE values are close to satellite observations. During March the best representation of the observed data was obtained by MIROC5 and BESM-OA V2.5 models. 


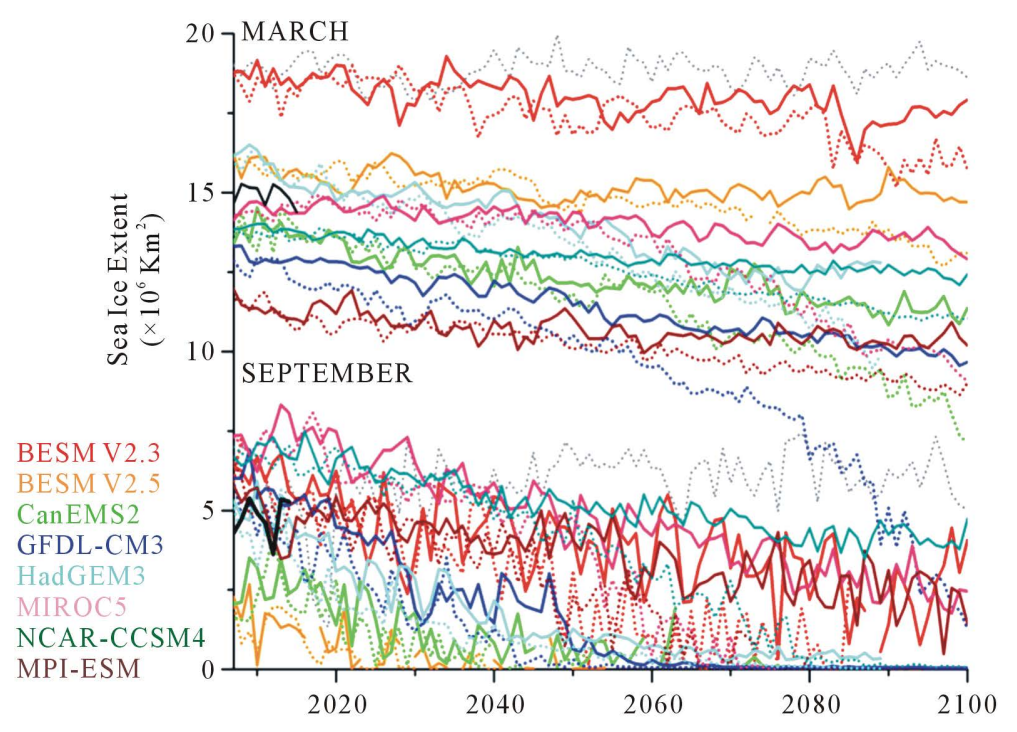

Figure 7. Time series of modeled Arctic SIE in September and March from 2006 to 2100, using Representative Concentration Pathways RCP4.5 (solid lines) and RCP8.5 (dash lines). Black lines are the satellite observations and gray lines refer to the control run of the BESM-OA V2.3.

During the first 30 years of the series, values from both RCPs are very similar in March and September months. For March, the SIE in the first years of the 21st century ranges from $11.8 \times 10^{6} \mathrm{~km}^{2}$ (MPI-ESM-LR) to $18.8 \times 10^{6} \mathrm{~km}^{2}$ (BESM-OA V2.3) in the RCP45 simulation. For the RCP8.5 simulation they vary between $11.7 \times$ $10^{6} \mathrm{~km}^{2}$ (MPI-ESM-LR) and $18.4 \times 10^{6} \mathrm{~km}^{2}$ (BESM-OA V2.3). For September SIE values vary from approximately $2 \times 10^{6} \mathrm{~km}^{2}$ (BESM-OA V2.3) to $6.7 \times 10^{6} \mathrm{~km}^{2}$ (MIROC 5). Already during these early years, it is possible to observe the discrepancy between the two different BESM configurations.

For all RCP simulations, BESM-OA V2.3 and BESM-OA V2.5 show higher (lower) values in SIE during March (September) when compared to other models used in this work. The models reveal strong amplitudes in SIE between different seasons. Both BESM simulations clearly present the higher values in March for all years. However, for September the higher SIE was found in MIROC5 model (similar amplitude was observed in MPI-ESM-LR model).

It is possible to observe a higher inter-annual variability in September than in March for all models, as well as for the early period's satellite observations. The changes in inter-annual variability are important for sea ice prediction and frequency and for assessing the frequency of occurrence of extreme SIE anomalies.

It is noteworthy that the models comparatively show different tendencies for the months of maximum and minimum SIE. For the month of March, the MPI-ESM-LR model presented the lowest values compared to the other models used here, whereas for the month of September the lowest values encountered are those of the BESM-OA V2.5 model. In general, when compared to the other CMIP5 models, the BESM-OA V2.3 model tends to overestimate SIE in March and September, for both RCP simulations.

From the year 2040 onward, all models show a dramatic shrinking in SIE in the RCP 8.5 scenario. This indicates a high sensitivity of sea ice cover in response to an increase in the atmospheric carbon dioxide. The GFDL-CM3 model clearly shows this abrupt decrease in SIE with the RCP8.5 scenario when compared to the RCP4.5 one. In this case, the decline is so strong that at the end of the 21st century the SIE maximum (in March) is similar to the minimum SIE (in September) found in the beginning of the 21st century. If the GFDL-CM3 model is reasonably correct, it means that the Arctic can be ice-free also during the coldest season of the year just after 2100 .

For September, ice-free conditions (defined as less than $0.5 \times 10^{6} \mathrm{~km}^{2}$ ) are obtained from 2020 in Can-ESM2 model, BESM-OA V2.5 and HAGEM2-2S with the RCP8.5 scenario. According to Chylek et al. [23] the addition of the land-vegetation model and terrestrial oceanic interactive carbon cycle to the coupled atmosphere-ocean in the Can-ESM2 model improved the simulations, although increased the overstimation of atmospheric warming after 1970. That explains the minimum values found here for CAN-ESM2 sea ice projections. 
Also focusing on the RCP8.5 scenario, most of the models show ice free situations, or episodes, after 2045 for the month of September. The exceptions are BESM-OA V2.3 and NCAR-CCSM4. These two models are a bit more conservative than the others, pointing out to ice free situations to starting after 2060.

It is expected that ice-free conditions will have strong effects on the global climate system though changes in both ocean and atmospheric circulations. It is known that sea ice loss amplifies the effects of radiative forcing by the albedo-sea ice feedback mechanism and cloud effects. It also, affects the meridional and inter-hemispheric temperature gradients that can affect mid-latitude circulation. However the quantification of these effects remains unclear requiring improvements in the global climate models.

\subsection{Surface Anomalies Temperatures}

In this section, we compare Surface Anomalies of Temperatures (SAT) for BESM-OA V2.3 and BESM-OA V2.5 to explain the differences between those versions in SIE presented in Figure 8.

Figure 8 shows SAT and Total Cloud Cover for BESM-OA 2.3 and BESM-OA 2.5 using future scenarios, relative to the period from 2006 to 2100. A marked warming in the northern high-latitudes is observed in both BESM versions, being notably stronger in the RCP8.5 simulation. This warming called Polar Amplification (PA) occurs due to the increase in the atmospheric greenhouse gas concentration, and is accompanied by an expressive reduction in SIE in both simulations (Figure 8). The relationship among air temperature rises and sea ice loss is evident and underpinned statistically [5]. PA is associated with several feedback processes as the ice-albedo feedback, temperature, water vapor and clouds. Most of studies indicate that the ice-albedo feedback is the main contributor for PA [2] [3] [9]. However Pithan and Maurtsen [55], using CMIP5 simulations found that, the major contributor to PA comes from air temperature feedbacks (as the surface warms, more energy is radiated into space in lower latitudes compared with the Arctic region).

When comparing the warming between the two BESM versions, we observe that higher amplitude values are observed in BESM-OA V2.5, particularly in high latitudes between $75^{\circ} \mathrm{N}$ to $90^{\circ} \mathrm{N}$. As a result of these warming discrepancies the SIE is lower in BESM-OA V2.5 than in BESM-OA V2.3 (Figure 7).

The microphysics of Ferrier et al. [31] and the new surface scheme based on Jimenez and Dudhia [32] used in BESM-OA V2.5 produced an improved in the representation of precipitation, wind, air temperature, humidity,
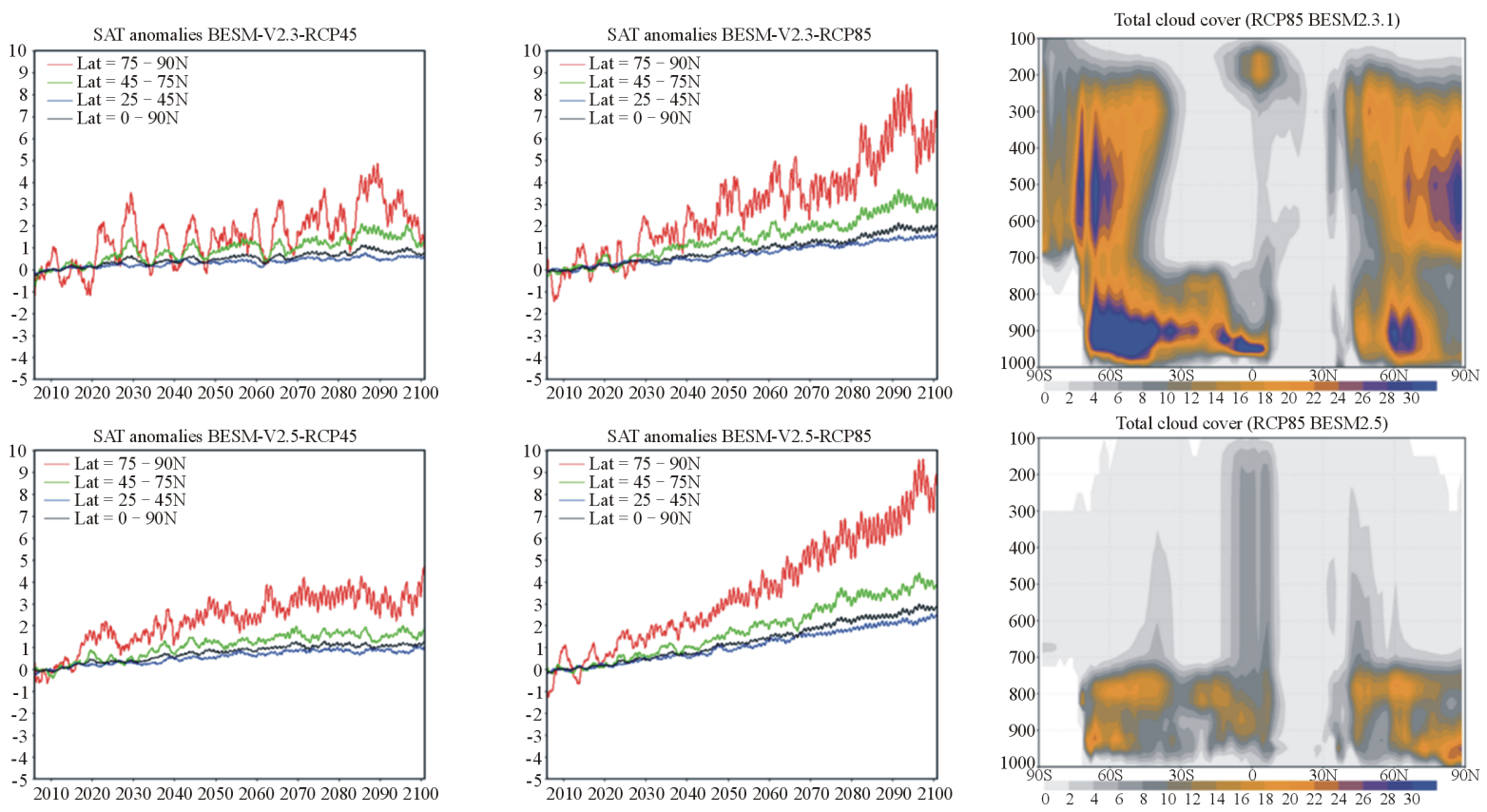

Figure 8. Surface Anomalies Temperature (SAT) and total cloud cover from January 2006 to December 2100 for BESM-OA V2.3 and BESM-OA V2. For SAT, the red lines represent the average for latitudes between $75^{\circ} \mathrm{N}$ to $90^{\circ} \mathrm{N}$. Green and blue lines are for latitudes between $45^{\circ} \mathrm{N}$ to $75^{\circ} \mathrm{N}$ and $25^{\circ} \mathrm{N}$ to $45^{\circ} \mathrm{N}$, respectively. Latitudes between $0^{\circ} \mathrm{N}$ to $90^{\circ} \mathrm{N}$ are represented by the black lines. 
and energy balance at the top of the atmosphere (not shown). A better representation of these variables exerts strong influences in coupling ocean-atmosphere-sea ice simulations and teleconnections with higher latitudes. The microphysics adopted in BESM-OA V2.5 produced a decrease in the total cloud cover in the Arctic region (Figure 8). This allows the ocean to absorb more heat from incident shortwave radiation and then contribute to a greater melting of the sea ice. The decrease in total cloud cover and consequent strong increase in SAT is consistent with the SIE reduction showed in Figure 7.

According to Jiang et al. [56], Clouds (in both ice and liquid forms) are important modulators of the climate system and are involved in several feedback processes that affect the global atmospheric circulation and the energy budget. Improving the cloud microphysics in Coupled Climate Models result in an advance in climate prediction and reduce the uncertainties in future projections. As recently pointed out by Eyring et al. [57], the understanding of the role of the clouds in the general atmospheric circulation, climate sensitivity and assessing the response of the cryosphere system to a warming climate, are among the greatest challenges for CMIP6.

\section{Conclusion}

In this work, we evaluated the decadal simulation (1980-2014) and assessed the future climate projections (20062100) generated by BESM-OA and CMIP5 models. BESM-OA V2.3 results for the seasonal cycle are consistent with satellites observations and the other CMIP5 models, however almost all models tend to overestimate SIE in March in relation to observations. Based on our results and [42] [43] [45], we suggest that the winter Arctic SIE bias is related to a LW radiation bias in climate models. Spatial patterns of climatological averages at the end of the melting season presented a deficiency in capturing the correct signature of the minimum SIE record, as well a model systematic model error between Beaufort Sea and East Siberia (Figure 4 and Figure 6). Future scenarios show an abrupt shrinking of the sea ice and ice-free summer conditions from the year 2045 and onwards, for both RCPs projections. This is a result of the internal climate response to the changing in radiative forcing throughout the years. Polar Amplification and feedback processes explain the rapid Arctic sea ice loss, despite the uncertainties and limitations of Global Climate Models. The sea ice responses are different in CMIP5 models due to differences in the ocean, atmosphere, sea ice conditions, as well the coupling between the components in each model. Future progress in sea ice modeling is essential and requires advances in the parameterizations of climate feedback processes. The climate in the Arctic region will change even more and will induce complex changes in the global climate, thereafter will induce changes in Arctic climate over again. In synthesis, we can say that the Arctic region and its climate are way more complex than forecasted.

\section{Acknowledgements}

This research was partially funded by the National Council for Scientific and Technological Development (IBAS/ CNPq), Research Program for Global Climate Change/Sao Paulo Research Foundation (PFPMCG/FAPESP), Climate Change Brazilian Network (RedeClima), National Institute for Climate Change (INCT-Clima).

\section{References}

[1] Stroeve, J.C., Kattsov, V., Barrett, A., Serreze, M., Pavlova, T., Holland, M. and Meier, W.N. (2012) Trends in Arctic Sea Ice Extent from CMIP5, CMIP3 and Observations. Geophysical Research Letters, 39, L16502. http://dx.doi.org/10.1029/2012GL052676

[2] Serreze, M.C. and Barry, R.G. (2011) Processes and Impacts of Arctic Amplification: A Research Synthesis. Global and Planetary Change, 77, 85-96. http://dx.doi.org/10.1016/j.gloplacha.2011.03.004

[3] Holland, M.M. and Bitz, C.M. (2003) Polar Amplification of Climate Change in the Coupled Model Intercomparison Project. Climate Dynamics, 21, 221-232. http://dx.doi.org/10.1007/s00382-003-0332-6

[4] Notz, D. and Marotzke, J. (2012) Observations Reveal External Driver for Arctic Sea-Ice Retreat. Geophysical Research Letters, 39, L08502. http://dx.doi.org/10.1029/2012GL051094

[5] Doescher, R., Vihma, T. and Maksimovich, E. (2014) Recent Advances in Understanding the Arctic Climate System State and Change from a Sea Ice Perspective: A Review. Atmospheric Chemistry And Physics, 14, 13571-13600. http://dx.doi.org/10.5194/acp-14-13571-2014

[6] Stroeve, J., Holland, M.M., Meier, W., Scambos, T. and Serreze, M. (2007) Arctic Sea Ice Decline: Faster than Forecast. Geophysical Research Letters, 34, L09501. http://dx.doi.org/10.1029/2007GL029703

[7] Perovich, D.K. (2011) The Changing Arctic Sea Ice Cover. Oceanography, 24,162-173. 
http://dx.doi.org/10.5670/oceanog.2011.68

[8] Kinnard, C., Zdanowicz, C.M., Fisher, D.A., Isaksson, E., de Vernal, A. and Thompson, L.G. (2011) Reconstructed Changes in Arctic Sea Ice over the Past 1450 Years. Nature, 479, 509-512. http://dx.doi.org/10.1038/nature10581

[9] Curry, J.A., Schramm, J.L. and Ebert, E.E. (1995) Sea Ice Albedo Climate Feedback Mechanism. Journal of Climate, 8, 240-247. http://dx.doi.org/10.1175/1520-0442(1995)008<0240:SIACFM>2.0.CO;2

[10] Tang, Q., Zhang, X., Yang, X. and Francis, J.A. (2013) Cold Winter Extremes in Northern Continents Linked to Arctic Sea Ice Loss. Environmental Research Letters, 8, Article ID: 014036. http://dx.doi.org/10.1088/1748-9326/8/1/014036

[11] Cohen, J.L., Furtado, J.C., Barlow, M.A., Alexeev, V.A. and Cherry, J.E. (2012) Arctic Warming, Increasing Snow Cover and Widespread Boreal Winter Cooling. Environmental Research Letters, 7, Article ID: 014007. http://dx.doi.org/10.1088/1748-9326/7/1/014007

[12] Tang, Q., Zhang, X. and Francis, J.A. (2014) Extreme Summer Weather in Northern Mid-Latitudes Linked to a Vanishing Cryosphere. Nature Climate Change, 4, 45-50. http://dx.doi.org/10.1038/nclimate2065

[13] Screen, J.A. (2013) Influence of Arctic Sea Ice on European Summer Precipitation. Environmental Research Letters, 8, Article ID: 044015. http://dx.doi.org/10.1088/1748-9326/8/4/044015

[14] ACIA (Arctic Climate Impact Assessment) (2005) Arctic Climate Impact Assessment. Cambridge University Press, Cambridge, $1042 \mathrm{p}$.

[15] Meier, W.N., Hovelsrud, G.K., van Oort, B.E.H., Key, J.R., Kovacs, K.M., Michel, C., Haas, C., Granskog, M.A., Gerland, S., Perovich, D.K., Makshtas, A. and Reist, J.D. (2014) Arctic Sea Ice in Transformation: A Review of Recent Observed Changes and Impacts on Biology and Human Activity. Reviews of Geophysics, 52, 185-217. http://dx.doi.org/10.1002/2013RG000431

[16] Cochran, P., Huntington, O.H., Pungowiyi, C., Tom, S., Chapin III, F.S., Huntington, H.P., Maynard, N.G. and Trainor, S.F. (2013) Indigenous Frameworks for Observing and Responding to Climate Change in Alaska. Climatic Change, 120, 557-567. http://dx.doi.org/10.1007/s10584-013-0735-2

[17] Whiteman, G., Hope, C. and Wadhams, P. (2013) Climate Science: Vast Costs of Arctic Change. Nature, 499, $401-403$. http://dx.doi.org/10.1038/499401a

[18] Nobre, P., Siqueira, L.S., de Almeida, R.A., Malagutti, M., Giarolla, E., Castelão, G.P., et al. (2013) Climate Simulation and Change in the Brazilian Climate Model. Journal of Climate, 26, 6716-6732. http://dx.doi.org/10.1175/JCLI-D-12-00580.1

[19] Vaughan, D.G., Comiso, J.C., Allison, I., Carrasco, J., Kaser, G., Kwok, R., Mote, P., Murray, T., Paul, F., Ren, J., Rignot, E., Solomina, O., Steffen, K. and Zhang, T. (2013) Observations: Cryosphere. In: Stocker, T.F., Qin, D., Plattner, G.-K., Tignor, M., Allen, S.K., Boschung, J., Nauels, A., Xia, Y., Bex, V. and Midgley, P.M., Eds., Climate Change 2013: The Physical Science Basis, Contribution of Working Group I to the Fifth Assessment Report of the Intergovernmental Panel on Climate Change, Cambridge University Press, Cambridge, United Kingdom and New York, 317-382.

[20] Taylor, K.E., Stouffer, R.J. and Meehl, G.A. (2012) An Overview of CMIP5 and the Experiment Design. Bulletin of the American Meteorological Society, 93, 485-498. http://dx.doi.org/10.1175/BAMS-D-11-00094.1

[21] Taylor, K.E., Stouffer, R.J. and Meehl, G.A. (2009) A Summary of the CMIP5 Experiment Design. CMIP Report, 30 p.

[22] Merryfield, W.J., Lee, W.S., Boer, G.J., Kharin, V.V., Scinocca, J.F., Flato, G.M., Ajayamohan, R.S. and Fyfe, J.C. (2013) The Canadian Seasonal to Interannual Prediction System. Part I: Models and Initialization. Monthly Weather Review, 141, 2910-2945. http://dx.doi.org/10.1175/MWR-D-12-00216.1

[23] Chylek, P., Li, J., Dubey, M.K., Wang, M. and Lesins, G. (2011) Observed and Model Simulated 20th Century Arctic Temperature Variability: Canadian Earth System Model CanESM2. Atmospheric Chemistry and Physics Discussions, 11, 22893-22907. http://dx.doi.org/10.5194/acpd-11-22893-2011

[24] Delworth, T.L., Broccoli, A.J., Rosati, A., Stouffer, R.J., Balaji, V., Beesley, J.A., et al. (2006) GFDL’s CM2 Global Coupled Climate Models. Part I: Formulation and Simulation Characteristics. Journal of Climate, 19, 643-674. http://dx.doi.org/10.1175/JCLI3629.1

[25] Griffies, S.M., Winton, M., Donner, L.J., Horowitz, L.W., Downes, S.M., Farneti, R., et al. (2011) The GFDL CM3 Coupled Climate Model: Characteristics of the Ocean and Sea Ice Simulations. Journal of Climate, 24, 3520-3544. http://dx.doi.org/10.1175/2011JCLI3964.1

[26] Gordon, C., Cooper, C., Senior, C., Banks, H., Gregory, J., Johns, T., Mitchell, J. and Wood, R. (2000) The Simulation of SST, Sea Ice Extents and Ocean Heat Transports in a Coupled Model without Flux Adjustments. Climate Dynamics, 16, 147-168. http://dx.doi.org/10.1007/s003820050010

[27] Collins, W.J., Bellouin, N., Doutriaux-Boucher, M., Gedney, N., Halloran, P., Hinton, T., et al. (2011) Development 
and Evaluation of an Earth-System Model-HadGEM2. Geoscientific Model Development, 4, 1051-1075. http://dx.doi.org/10.5194/gmd-4-1051-2011

[28] Watanabe, M., Suzuki, T., O’ishi, R., Komuro, Y., Watanabe, S., Emori, S., Takemura, T., Chikira, M., Ogura, T., Sekiguchi, M., Takata, K., Yamazaki, D., Yokohata, T., Nozawa, T., Hasumi, H., Tatebe, H. and Kimoto, M. (2010) Improved Climate Simulation by MIROC5 Mean States, Variability, and Climate Sensitivity. Journal of Climate, 23, 6312-6335. http://dx.doi.org/10.1175/2010JCLI3679.1

[29] Marsland, S.J., Haak, H., Jungclaus, J.H., Latif, M. and Röske, F. (2003) The Max-Planck-Institute Global Ocean/Sea Ice Model with Orthogonal Curvilinear Coordinates. Ocean Modelling, 5, 91-127. http://dx.doi.org/10.1016/S1463-5003(02)00015-X

[30] Gent, P.R., Danabasoglu, G., Donner, L.J., Holland, M.M., Hunke, E.C., Jayne, S.R., et al. (2011) The Community Climate System Model Version 4. Journal of Climate, 24, 4973-4991. http://dx.doi.org/10.1175/2011JCLI4083.1

[31] Ferrier, B.S., Jin, Y., Lin, Y., Black, T., Rogers, E. and DiMego, G. (2002) Implementation of a New Grid-Scale Cloud and Precipitation Scheme in the NCEP Eta Model. Preprints, 15th Conference on Numerical Weather Prediction, San Antonio, 12-16 August 2002, 280-283.

[32] Jiménez, P.A. and Dudhia, J. (2012) Improving the Representation of Resolved and Unresolved Topographic Effects on Surface Wind in the WRF Model. Journal of Applied Meteorology and Climatology, 51, 300-316. http://dx.doi.org/10.1175/JAMC-D-11-084.1

[33] Capistrano, V.B., Figueroa, S.N., Fernandez, J.P.R. and Nobre, P. (2015) The New Surface Layer Scheme of the Brazilian Earth System Model. The Surface Ocean-Lower Atmosphere Study (SOLAS), Kiel.

[34] Capistrano, V., Tedeschi, R., Silva, J., Nobre, P., Neto, O., Casagrande, F., Lanfer, A., Baptista, M., Figueroa, S. and Vial, J. (2016) Climate Sensitivity of the Brazilian Earth System Model. Version 2.5. "unpublished”.

[35] Griffies, S.M. (2009) Elements of MOM4p1. NOAA/Geophysical Fluid Dynamics Laboratory Ocean Group Technical Report No. 6, 444 p.

[36] Bottino, M. and Nobre, P. (2015) Impacts of Cloud Cover Schemes on the Atlantic Climate in the Brazilian Climate Model-BESM. “unpublished”.

[37] Winton, M. (2000) A Reformulated Three-Layer Sea Ice Model. Journal of Atmospheric and Oceanic Technology, 17, 525-531. http://dx.doi.org/10.1175/1520-0426(2000)017<0525:ARTLSI>2.0.CO;2

[38] Hunke, E.C. and Dukowicz, J.K. (1997) An Elastic-Viscous-Plastic Model for Sea Ice Dynamics. Journal of Physical Oceanography, 27, 1849-1867. http://dx.doi.org/10.1175/1520-0485(1997)027<1849:AEVPMF>2.0.CO;2

[39] Semtner, A.J. (1976) A Model for the Thermodynamic Growth of Sea Ice in Numerical Investigations of Climate. Journal of Physical Oceanography, 6, 27-37. http://dx.doi.org/10.1175/1520-0485(1976)006<0379:AMFTTG>2.0.CO;2

[40] Francis, J.A., Chan, W., Leathers, D.J., Miller, J.R. and Veron, D.E. (2009) Winter Northern Hemisphere Weather Patterns Remember Summer Arctic Sea-Ice Extent. Geophysical Research Letters, 36, L07503.

[41] Arzel, O., Fichefet, T. and Goosse, H. (2006) Sea Ice Evolution over the 20th and 21st Centuries as Simulated by Current AOGCMs. Ocean Modelling, 12, 401-415. http://dx.doi.org/10.1016/j.ocemod.2005.08.002

[42] Sorteberg, A., Kattsov, V., Walsh, J.E. and Pavlova, T. (2007) The Arctic Surface Energy Budget as Simulated with the IPCC AR4 AOGCMs. Climate Dynamics, 29, 131-156. http://dx.doi.org/10.1007/s00382-006-0222-9

[43] Karlsson, J. and Svensson, G. (2013) Consequences of Poor Representation of Arctic Sea-Ice Albedo and Cloud-Radiation Interactions in the CMIP5 Model Ensemble. Geophysical Research Letters, 40, 4374-4379. http://dx.doi.org/10.1002/grl.50768

[44] Li, J.L., Waliser, D.E., Stephens, G., Lee, S., L’Ecuyer, T., Kato, S., Loeb, N. and Ma, H.Y. (2013) Characterizing and Understanding Radiation Budget Biases in CMIP3/CMIP5 GCMs, Contemporary GCM, and Reanalysis. Journal of Geophysical Research: Atmospheres, 118, 8166-8184. http://dx.doi.org/10.1002/jgrd.50378

[45] Wild, M., Ohmura, A., Gilgen, H., Morcrette, J.J. and Slingo, A. (2001) Evaluation of Downward Longwave Radiation in General Circulation Models. Journal of Climate, 14, 3227-3239. http://dx.doi.org/10.1175/1520-0442(2001)014<3227:EODLRI>2.0.CO;2

[46] Knutti, R. and Sedláček, J. (2013) Robustness and Uncertainties in the New CMIP5 Climate Model Projections. Nature Climate Change, 3, 369-373. http://dx.doi.org/10.1038/nclimate1716

[47] Shu, Q., Song, Z. and Qiao, F. (2015) Assessment of Sea Ice Simulations in the CMIP5 Models. The Cryosphere, 9, 399-409. http://dx.doi.org/10.5194/tc-9-399-2015

[48] Tietsche, S., Day, J.J., Guemas, V., Hurlin, W.J., Keeley, S.P.E., Matei, D., Msadek, R., Collins, M. and Hawkins, E. (2014) Seasonal to Interannual Arctic Sea Ice Predictability in Current Global Climate Models. Geophysical Research Letters, 41, 1035-1043. http://dx.doi.org/10.1002/2013GL058755 
[49] Cavalieri, D.J. and Parkinson, C.L. (2012) Arctic Sea Ice Variability and Trends, 1979-2010. Cryosphere, 6, 881-889. http://dx.doi.org/10.5194/tc-6-881-2012

[50] Holland, M.M., Bitz, C.M. and Tremblay, B. (2006) Future Abrupt Reductions in the Summer Arctic Sea Ice. Geophysical Research Letters, 33, L23503. http://dx.doi.org/10.1029/2006gl028024

[51] Vihma, T. (2014) Effects of Arctic Sea Ice Decline on Weather and Climate: A Review. Surveys in Geophysics, 35, 1175-1214. http://dx.doi.org/10.1007/s10712-014-9284-0

[52] Hunke, E.C., Lipscomb, W.H. and Turner, A.K. (2010) Sea-Ice Models for Climate Study: Retrospective and New Directions. Journal of Glaciology, 56, 1162-1172. http://dx.doi.org/10.3189/002214311796406095

[53] Flocco, D., Schroeder, D., Feltham, D.L. and Hunke, E.C. (2012) Impact of Melt Ponds on Arctic Sea Ice Simulations from 1990 to 2007. Journal of Geophysical Research: Oceans, 117, C09032. http://dx.doi.org/10.1029/2012jc008195

[54] Roeckner, E., Mauritsen, T., Esch, M. and Brokopf, R. (2012) Impact of Melt Ponds on Arctic Sea Ice in Past and Future Climates as Simulated by MPI-ESM. Journal of Advances in Modeling Earth Systems, 4, M00A02. http://dx.doi.org/10.1029/2012ms000157

[55] Pithan, F. and Mauritsen, T. (2014) Arctic Amplification Dominated by Temperature Feedbacks in Contemporary Climate Models. Nature Geoscience, 7, 181-184. http://dx.doi.org/10.1038/ngeo2071

[56] Jiang, J.H., Su, H., Zhai, C., Perun, V.S., Del Genio, A., Nazarenko, L.S., et al. (2012) Evaluation of Cloud and Water Vapor Simulations in CMIP5 Climate Models Using NASA “A-Train” Satellite Observations. Journal of Geophysical Research: Atmospheres, 117, D14105. http://dx.doi.org/10.1029/2011jd017237

[57] Eyring, V., Bony, S., Meehl, G.A., Senior, C., Stevens, B., Stouffer, R.J. and Taylor, K.E. (2015) Overview of the Coupled Model Intercomparison Project Phase 6 (CMIP6) Experimental Design and Organisation. Geoscientific Model Development, 8, 10539-10583. http://dx.doi.org/10.5194/gmdd-8-10539-2015 